\title{
Surgery for colorectal liver metastases: the impact of resection margins on recurrence and overall survival
}

\author{
Jon-Helge Angelsen ${ }^{1,2^{*}}$, Arild Horn' ${ }^{1}$ Geir Egil Eide ${ }^{3,4}$ and Asgaut Viste ${ }^{1,2}$
}

\begin{abstract}
Background: Several reports have presented conflicting results regarding the association between resection margins (RMs) and outcome after surgery for colorectal liver metastases (CLM), especially in the era of modern chemotherapy. The purpose of this study was to evaluate the impact of RMs on overall survival (OS), time to recurrence (TTR) and local recurrence (LR) status, particularly for patients treated with preoperative chemotherapy.

Methods: A combined retrospective (1998 to 2008) and prospective (2008 to 2010) cohort study of consecutive patients with CLM without extrahepatic disease treated with primary resection at a medium volume centre.

Results: A total of 253 patients with known R status and 242 patients with defined margin width were included in the study. Patients were stratified according to margin width; A: R1, <1 mm ( $n=48,19 \%), B: 1$ to $4 \mathrm{~mm}(n=77)$, C: 5 to $9 \mathrm{~mm}(\mathrm{n}=46)$ and $\mathrm{D}: \geq 10 \mathrm{~mm}(\mathrm{n}=71)$. Median time to recurrence was 12.8 months, and after five years $21.5 \%$ had no recurrence. LR (inclusive combined recurrence in other hepatic sites or extrahepatic) occurred in 40 (16.5\%) cases, most frequently seen with RMs below $5 \mathrm{~mm}$. Five-year OS was $42.5 \%$ in R0 and $16.1 \%$ in R1 resections $(P=0.011)$. Patients were also stratified according to preoperative chemotherapy $(n=88)$, and the difference in five-year OS between RO (45.1\%) and R1 (14.7\%) was maintained ( $P=0.037)$. By multiple Cox regression analysis R1 resections tended to an adverse outcome $(P=0.067)$, also when adjusting for preoperative chemotherapy $(P=0.081)$.
\end{abstract}

Conclusions: R1 resections for colorectal liver metastases predict adverse outcome. RMs below $5 \mathrm{~mm}$ increased the risk for LR and shortened the time to recurrence. Preoperative chemotherapy did not alter an adverse outcome in R1 vs. R0 patients.

Keywords: Colorectal liver metastases, Resection margin, Overall survival, Local recurrence, Time to recurrence, Preoperative chemotherapy

\section{Background}

Resection for colorectal liver metastases (CLM) has been well established during the last three decades, with a reported five-year survival of up to $64 \%$, depending on selection criteria and preoperative risk factors [1-3]. In all intended curative cancer surgery a complete removal of the tumor is of major importance. During the 1980s and 1990s authors recommended 'the $1 \mathrm{~cm}$ rule' [4-7] that probably resulted in rejection of many patients from

\footnotetext{
* Correspondence: jhangelsen@gmail.com

'Department of Acute and Digestive Surgery, Haukeland University Hospital, N-5021 Bergen, Norway

${ }^{2}$ Department of Clinical Medicine, University of Bergen, N-5020 Bergen, Norway

Full list of author information is available at the end of the article
}

CLM surgery. Several reports from the last decade have shown that resection margins (RMs) are less important as long as R0 status is obtained [1,8-11]. In other reports $2 \mathrm{~mm}$ [12] and $5 \mathrm{~mm}$ [13] have been suggested as sufficient. Finally, some authors have even justified intended R1 resection following great progress in pre- and postoperative chemotherapy treatment due to an acceptable long-term outcome [14-16].

In an advanced stage IV cancer disease like CLM most patients are beyond curative treatment. In patients with resectable metastases, the surgical approach and the RMs are some of the few non-biological factors influenced by the surgeon. The purpose of this manuscript was therefore to analyse in detail the local recurrence (LR) pattern, 
time to recurrence (TTR) and overall survival (OS) with respect to the R1/R0 status and the magnitude of free RMs in patients with primary resection for CLM. We also wanted to explore whether chemotherapy altered the RMs impact on survival.

\section{Methods}

Haukeland University Hospital is a tertiary referral centre located in Western Norway, and serves a population of one million. This study is a patient-based cohort with a consecutive series of patients with CLM treated at a single institution (1998 to 2010). Data from the period 1998 to 2008 were retrospectively recorded, and prospectively collected from 2008 to 2010. Data were retrieved from the patients' medical records. All patients were prospectively followed up with respect to survival and other characteristics until November 2012. Variables analysed were TNM stage of primary tumour, time in months between resection of primary tumor and diagnosis of liver metastases (disease-free interval), number and size of metastases, chemotherapy (number of cycles, response and indication), date of liver resection, complications and in-hospital mortality, recurrence and death (perioperative, cancerrelated and other causes). RM status was obtained from the microscopic measurements in the histological reports. RMs $<1 \mathrm{~mm}$ were defined as positive (R1), in accordance with Pawlik et al. [9].

\section{Preoperative evaluation}

The selection criteria for surgery in our centre included a sufficient remaining tumour-free liver volume (30\%) with adequate blood perfusion and bile drainage, and absence of: a) non-resectable extrahepatic metastases, and/or b) no disseminated disease as evaluated preoperatively. Patients with extrahepatic disease and R2 resections were excluded from the current study. Preoperative investigations included computed tomography (CT) scan of the chest and abdomen/pelvis, and tumour marker analysis (CEA: carcinoembryonal antigen). In cases with an inconclusive CT scan, magnetic resonance imaging (MRI) of the liver, contrast-enhanced ultrasound and 18 F-fluorodeoxyglucose ${ }^{18}$ (FDG)-positron emission tomography (PET)/CT scan were performed. Each patient was discussed in a multidisciplinary team meeting with surgeons, oncologists and radiologists.

\section{Chemotherapy}

Preoperative chemotherapy ( $\mathrm{n}=88)$ was given in a perioperative setting $(n=43)$ or as a downstaging procedure $(n=40)$ in patients with initially deemed unresectable disease. Five patients developed CLM during adjuvant treatment with chemotherapy after resection of stage III colon cancer. We evaluated the outcome of chemotherapy by the Response Evaluation Criteria in Solid Tumour
(RECIST) version 1.1 [17]. The size of the metastases was measured on CT scan by dedicated radiologists. All patients in the perioperative group were offered the FOLFOX regimen (fluorouracil, leucovorin and oxaliplatin) with an intended six cycles before and after surgery. They were evaluated with CT scan after three and six cycles. The indication for perioperative chemotherapy has changed during the period. A total of 17 patients were enrolled in the European Organisation for Research and Treatment of Cancer (EORTC) multicentre study 40983 and randomised for surgery alone $(n=7)$, or surgery with perioperative chemotherapy $(\mathrm{n}=10)$ in the period 2001 to 2004 [18]. After that, patients $<76$ years with Eastern Cooperative Oncology Group (ECOG) performance status 0 to 1 and no previous treatment with oxaliplatin had been offered perioperative chemotherapy. In the downstaging group, patients were treated with several different chemotherapy regimens as listed in Table 1. First-line treatment with the Nordic FLOX or FLIRI regimen was most commonly used, optionally in combination with EGFR (endothelial growth factor receptor) inhibitors or angiogenesis inhibitors.

\section{Surgical procedures}

Surgical techniques included subcostal incision, intraoperative ultrasonography, occasionally repeated inflow control (the Pringle manoeuvre), and transection using Ultracision, Kelly clamp and Cavitron Ultrasonic Surgical Aspirator (CUSA). Throughout the period we have intended to achieve a parenchyma-sparing approach, with wedge resections whenever possible. Formal resections (hemihepatectomies or lobectomies) have been reserved for metastases placed centrally or near the hepatic veins. To increase intended complete tumour eradication, intraoperative radiofrequency ablation, and portal vein ligations/embolization with two-stage resections have been performed. Simultaneous colorectal cancer surgery has been reserved for healthy patients with colon cancer and less advanced CLM. Further details are listed in Table 1.

\section{Surveillance}

Follow-up after surgery included CT scan of the chest, abdomen and pelvis every three months for the first two years, and thereafter every six months for the next three years. Serum level of CEA tumour marker was obtained every third month. We defined LR by CT scan as a new lesion in contact with the previous resection surface. The resected area was easily detected with CT due to the wide use of metallic clips during the transection. The data were based on the first detection of recurrence. Data of recurrence were not available in four patients. Patterns of recurrence were stratified according to LR, hepatic recurrence (without LR) and extrahepatic recurrence. LR included patients with a) LR only, b) LR and 
Table 1 Clinical characteristics and administration of chemotherapy in $\mathbf{2 5 3}$ patients with primary resection for colorectal liver metastases

\begin{tabular}{|c|c|}
\hline Variable, statistics & Estimate \\
\hline Age in years, median (range) & $66.1(22.8,89.2)$ \\
\hline Gender male/female ratio & $133 / 120$ \\
\hline Synchronous metastases ${ }^{\mathrm{a}}, n(\%)$ & $115(45.5)$ \\
\hline Disease-free interval ${ }^{\mathrm{b}}$ in months, median (range) & $4(-14,131)$ \\
\hline \multicolumn{2}{|l|}{ Resections, $n$} \\
\hline Hemihepatectomy/lobectomy, $n(\%)$ & $117(46.2)$ \\
\hline Wedge/segment resections, $n$ (\%) & $136(53$ \\
\hline Simultaneous radiofrequency ablation, $n$ (\%) & $12(4$ \\
\hline Two-stage resections, $n$ (\%) & $3(1$ \\
\hline Simultaneous colorectal cancer surgery, $n(\%)$ & $14(5$ \\
\hline Extent of resection margin in mm, median (range) & $4(0-50)$ \\
\hline Number of metastases, median (range) & $2(1$ \\
\hline Metastases diameter in cm, median (range) & $3.0(0.2,15$. \\
\hline Bilobar metastases, $n$ (\%) & $94(37$ \\
\hline Number of resections/patient (1/2/3/4/5) & 203/36/11/ \\
\hline In-hospital mortality, n (\%) & $4(1$. \\
\hline Follow-up survivors in years, median (range) & $4.7(1.9-1)$ \\
\hline Chemotherapy preoperatively, $n$ (\%) & $88(34$ \\
\hline Downstaging, $n(\%)$ & $40(15.8)$ \\
\hline Perioperative ${ }^{c}, n(\%)$ & $43(17.0)$ \\
\hline Adjuvant after colon surgery, $n$ (\%) & $5(2$ \\
\hline \multicolumn{2}{|l|}{ Type of chemotherapy } \\
\hline FOLFOX $^{d}, n(\%)$ & $71(81.6)$ \\
\hline FOLFIRI ${ }^{\mathrm{e}} /+$ bevacizumab, $n$ (\%) & $8 / 3(9.1 / 3.4)$ \\
\hline FOLFIRI + cetuximab, $n(\%)$ & $1(1$ \\
\hline FLV,$n(\%)$ & $3(3$ \\
\hline Other combinations, $n$ (\%) & $5(5.7)$ \\
\hline \multicolumn{2}{|l|}{ Outcome of chemotherapy ${ }^{g}$ (RECIST) } \\
\hline Partial response, $n(\%)$ & $52(59.1)$ \\
\hline Stable disease, $n$ (\%) & $32(36.4)$ \\
\hline Progression, $n$ (\%) & $2(2$ \\
\hline Unknown, n (\%) & $2(2$ \\
\hline \multicolumn{2}{|l|}{ Number of cycles } \\
\hline$\leq 3$ & $11(12.5)$ \\
\hline $4-6$ & $40(45.4)$ \\
\hline $7-12$ & $27(30.7)$ \\
\hline$>12$ & \\
\hline Unknown & \\
\hline
\end{tabular}

Table 1 Clinical characteristics and administration of chemotherapy in $\mathbf{2 5 3}$ patients with primary resection for colorectal liver metastases (Continued)

\begin{tabular}{cr}
\hline Chemotherapy adjuvant, $n(\%)$ & $44(17.4)$ \\
After neoadjuvant, $n(\%)$ & $30(11.9)$ \\
After downstaging, $n(\%)$ & $7(2.8)$ \\
Without preoperative chemotherapy, $n(\%)$ & $7(2.8)$ \\
\hline
\end{tabular}

${ }^{a}$ Synchronous metastases: detected $<1$ month after surgery of primary colorectal

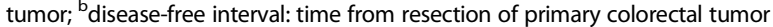
to detection of hepatic metastases; ${ }^{c}$ all patients were offered the FOLFOX regimen; ${ }^{\mathrm{d}}$ FOLFOX (oxaliplatin, 5 -fluorouracil, leukovorin); ${ }^{\mathrm{e}} \mathrm{FOLFIRI} \mathrm{(irinotecan,}$ 5 -fluorouracil, leukovorin); ${ }^{\text {fFLV }}$ (5-fluorouracil, leukovorin); ${ }^{9}$ RECIST-criteria measured by computed tomography scan.

relapse in other sites of the liver and c) LR with concomitant new extrahepatic lesions. During the follow-up, thirteen patients died from causes other than colorectal cancer, and six from treatment-related causes. These patients were also included in the analysis of OS, according to the definition stated by Punt et al. [19].

\section{Statistical analysis}

Variables with possible impact on OS like RM, age, size, number of metastases, bilobar distribution, disease-free interval and TNM stage of primary tumour were analysed with univariate and multivariate survival methods. The exact chi-square $\left(\chi^{2}\right)$ test was used for categorical variables, the $t$ test for normally distributed variables, and the Mann-Whitney $U$ (MWU) test for non-normally distributed continuous variables. The Kruskal-Wallis one-way analysis of variance test was used to compare more than two non-normally distributed samples. Multinomial logistic regression was used to evaluate LR in relation to RMs. Survival was estimated by the Kaplan-Meier method [20] and tested for significance with the log-rank test [21]. Multivariate analysis was performed as Cox proportional regression [22]. Continuous predictors such as RMs were also modelled using multiple fractional polynomial regressions [23]. A $P$ value $\leq 0.05$ was considered significant. OS was defined as time from resection to death irrespective of cause, and TTR was defined as the interval between resection and the detection of a local or distant relapse [19]. All analyses were performed using SPSS Statistics version 19 (IBM Corp., Armonk, NY, USA) and Stata 12 statistical software (StataCorp, College Station, TX, USA). We decided to use TTR rather than disease-free survival as a parameter in assessing recurrence patterns, since the latter has treatment-related and non-cancer-related deaths as endpoints, which could be misleading according to the definition by Punt et al. [19].

\section{Ethics}

The Regional Committee of Ethics of Western Norway Health Authority approved the study, with an exemption to the requirement for obtaining informed consent from 
patients included in the retrospective part (1998 to 2008). In the prospective part (2008 to 2010) patients were enrolled through written consent.

\section{Results}

In total, 278 patients underwent 353 resections in the 13-year period. Among these, 270 patients underwent a primary (first) liver resection. Eight patients were admitted from other hospitals for re-resections. Fourteen patients $(5.2 \%)$ with primary resectable extrahepatic metastases (thirteen pulmonary and one pelvic) were not included in the current study. One patient could not complete the second procedure of a two-stage liver resection due to progression of disease. The R0/R1 status was not obtained in two patients, whereas the exact resection margin (in millimetres) could not be defined in eleven cases.

Finally, a total of 253 patients with known R status and 242 patients with a defined margin width were eligible for further analysis. Patients were further sub-grouped according to margin width obtained from the histological report; A: R1, <1 mm ( $\mathrm{n}=48), \mathrm{B}: 1$ to $4 \mathrm{~mm}(\mathrm{n}=77), C: 5$ to $9 \mathrm{~mm}(\mathrm{n}=46)$ and $\mathrm{D}: \geq 10 \mathrm{~mm}(\mathrm{n}=71)$. Clinical and pathological features are listed in Table 1. Positive microscopic margins (R1) were found in 48 cases (19.0\%).

\section{Patient and tumour demographics}

R1 patients had more advanced disease compared to R0 according to bilobar locations $\left(P=0.007, X^{2}\right.$-test $)$ and number of metastases $(P=0.099$, MWU test). There was no significant difference between R0 and R1 patients in the TNM status of primary tumour in colon or rectum, American Society of Anesthesiologists (ASA) score, size of the metastases and the use of preoperative chemotherapy. Postoperative chemotherapy was administered more frequently in $\mathrm{R} 1$ patients ( $\mathrm{n}=12$ of $48,25.0 \%$ ) compared to R0 ( $\mathrm{n}=31$ of $205,15.1 \%), P=0.016, \chi^{2}$-test. In the chemotherapy group, there was no difference in number of $\mathrm{R} 1$ resections between patients with partial response or stable disease using the RECIST criteria $\left(P=0.575, X^{2}\right.$-test $)$. In the perioperative and the downstaging group a total of thirty (69.8\%) and seven (17.5\%) patients, respectively, underwent postoperative chemotherapy $\left(P<0.0001, \chi^{2}\right.$-test).

\section{Patterns of recurrence}

Global recurrent disease occurred in $\mathrm{n}=175$ (72.3\%) patients, whereas involvement of the resection surface was found in 40 cases (16.5\%). Further details are listed in Table 2. We found a lower global recurrence in the groups $\mathrm{C}$ and D compared to A and B. The risk for recurrence according to RMs (A to D) was assessed with a multinomial logistic regression, as detailed in Table 3. The odds ratios for LR were significantly higher in groups A and $B$ relative to group D. RMs did not seem to impact hepatic recurrence, whereas extrahepatic recurrence was more frequent compared to no recurrence with RMs $<5 \mathrm{~mm}$ $(0.005)$. A total of $21.5 \%$ of the patients were recurrencefree after five years. TTR increased significantly $(P=0.009)$ with the increasing extent of the RMs (Figure 1a), but this difference was repealed when we omitted those patients ( $\mathrm{n}=40)$ with all kinds of LR $(P=0.097)$. We also detected a non-significant difference in five-year TTR between R0 (24.5\%) and R1 (0\%, $P=0.127)$. No additional benefit for TTR was seen with RMs beyond $10 \mathrm{~mm}$, where the groups $\mathrm{C}$ and $\mathrm{D}$ were nearly equal in outcome (Figure 1a).

A total of 50 of $253(19.8 \%)$ patients underwent a second operation for resectable recurrence. Twenty (40.0\%) of these were due to LR after the first resection. In 27 cases

Table 2 Global recurrence and local recurrence (LR) following $\mathbf{n}=\mathbf{2 4 2}$ primary resections for colorectal liver metastases according to resection margins (RMs)

\begin{tabular}{|c|c|c|c|c|c|}
\hline \multirow[b]{2}{*}{ Recurrence } & \multicolumn{5}{|c|}{ Resection margins } \\
\hline & A (R1) n (\%) & B (1-4 mm) n (\%) & $\mathrm{C}(5-9 \mathrm{~mm}) \mathrm{n}(\%)$ & $\mathrm{D}(\geq 10 \mathrm{~mm}) \mathrm{n}(\%)$ & All $n(\%)$ \\
\hline LR only & $7(14.6)$ & $3(3.9)$ & $3(6.5)$ & $1(1.3)$ & $14(5.8)$ \\
\hline LR and hepatic & $3(6.3)$ & $3(3.9)$ & $3(6.5)$ & $1(1.3)$ & $10(4.1)$ \\
\hline LR and extrahepatic & $6(12.5)$ & $10(13.0)$ & $0(0.0)$ & $0(0.0)$ & $16(6.6)$ \\
\hline LR (total) ${ }^{1}$ & $16(33.3)$ & $16(20.7)$ & $6(13.0)$ & $2(2.8)$ & $40(16.5)$ \\
\hline Hepatic only & $8(16.7)$ & $15(19.5)$ & $7(15.2)$ & $22(31.0)$ & $52(21.5)$ \\
\hline Extrahepatic & $13(27.1)$ & $31(40.3)$ & $17(37.0)$ & $18(25.4)$ & 79 (32.6) \\
\hline Unknown & $2(4.2)$ & $1(1.3)$ & $0(0.0)$ & $1(1.3)$ & $4(1.7)$ \\
\hline Global $^{2}$ & $39(81.3)$ & $63(81.8)$ & $30(65.2)$ & $43(60.5)$ & $175(72.3)$ \\
\hline No recurrence & $9(18.8)$ & $14(18.2)$ & $16(34.8)$ & $28(39.4)$ & $67(27.7)$ \\
\hline Total & $48(100)$ & 77 (100) & $46(100)$ & $71(100)$ & $242(100)$ \\
\hline
\end{tabular}

Extrahepatic recurrence: recurrence outside the liver with or without hepatic involvement. Statistics: $P=0.0003\left(x^{2}\right.$ two-sided exact test) when all groups were included.

'LR (total): the sum of 'LR only', 'LR and hepatic' and 'LR and extrahepatic'.

${ }^{2}$ Global recurrence: the sum of 'LR (total)', 'hepatic only', 'extrahepatic', and 'unknown recurrence'. 
Table 3 Results from multinomial logistic regression of recurrence according to resection margins (RMs) in $n=242$ patients with known recurrence status after primary resection for colorectal liver metastases

\begin{tabular}{llccr}
\hline Recurrence $^{\dagger}$ & RM & OR & 95\% Cl & P value \\
\hline Local & R1, $<1 \mathrm{~mm}$ & 24.89 & $(4.77,129.69)$ & 0.0001 \\
$(\mathrm{n}=40)$ & $1-4 \mathrm{~mm}$ & 16.00 & $(3,22,79.56)$ & 0.001 \\
& $5-9 \mathrm{~mm}$ & 5.25 & $(0.95,29.15)$ & 0.058 \\
& $\geq 10 \mathrm{~mm}$ & 1.00 & Reference & \\
Hepatic only & $\mathrm{R} 1,<1 \mathrm{~mm}$ & 1.13 & $(0.38,3.42)$ & 0.827 \\
$(\mathrm{n}=52)$ & $1-4 \mathrm{~mm}$ & 1.36 & $(0.55,3.41)$ & 0.508 \\
& $5-9 \mathrm{~mm}$ & 0.56 & $(0.20,1.59)$ & 0.274 \\
& $\geq 10 \mathrm{~mm}$ & 1.00 & Reference & \\
Extrahepatic* & $\mathrm{R} 1,<1 \mathrm{~mm}$ & 2.25 & $(0.80,6.33)$ & 0.126 \\
$(\mathrm{n}=79)$ & $1-4 \mathrm{~mm}$ & 3.44 & $(1.45,8.18)$ & 0.005 \\
& $5-9 \mathrm{~mm}$ & 1.36 & $(0.67,4.08)$ & 0.276 \\
& $\geq 10 \mathrm{~mm}$ & 1.00 & Reference & \\
\hline
\end{tabular}

${ }^{\dagger}$ Reference category is 'no recurrence' $(n=67)$. Unknown recurrence pattern in $\mathrm{n}=4$ patients. *Extrahepatic: recurrence outside the liver with or without hepatic involvement. $\mathrm{RM}$, resection margins; $\mathrm{OR}$, odds ratio; $\mathrm{Cl}$, confidence interval.

(54.0\%), recurrence was found in other sites of the liver whereas only three patients $(6.0 \%)$ had combined intraand extrahepatic relapses. In patients with LR only, 11 of 14 (78.6\%) patients were resected. Of the 48 patients having a primary $\mathrm{R} 1$ resection, 15 (31.3\%) underwent a second operative procedure.

\section{Overall survival}

Five- and ten-year OS survival rates were $38.7 \%$ and $23.0 \%$, respectively, whereas median OS was 45.0 months. Fiveyear OS of R0 vs. R1 was $42.5 \%$ and $16.1 \%,(P=0.011$, Figure $1 \mathrm{~b}$ ), whereas median OS in R0 and R1 were 48.1 and 32.4 months, respectively. By sub-grouping according to margin width (A to D), an increased OS was seen in the univariate analysis $(P=0.035$, see Figure $1 b)$. However, there was no extra benefit when the RMs exceeded $10 \mathrm{~mm}$ (group $\mathrm{C}$ vs. D). Patients were also stratified according to preoperative chemotherapy $(n=88)$, and the difference in five-year OS between R0 and R1 was maintained $(P=0.037)$. In the perioperative group $(\mathrm{n}=43)$, a nonsignificant difference $(P=0.502)$ in five-year OS was seen between R1 (34.3\%) and R0 (54.2\%). In the downstaging group $(\mathrm{n}=40)$, the five-year OS was $40.2 \%$ for the R0 cases vs. none survivors in the R1 group $(P=0.017)$. Patients with initially unresectable metastases had more extensive disease evaluated as the average number of metastases (3.6) compared to the perioperative (2.5) and the surgery alone group (2.3), using Kruskal-Wallis test $(P=0.002)$. Positive RMs also predicted a borderline significant adverse outcome in the Cox proportional hazards

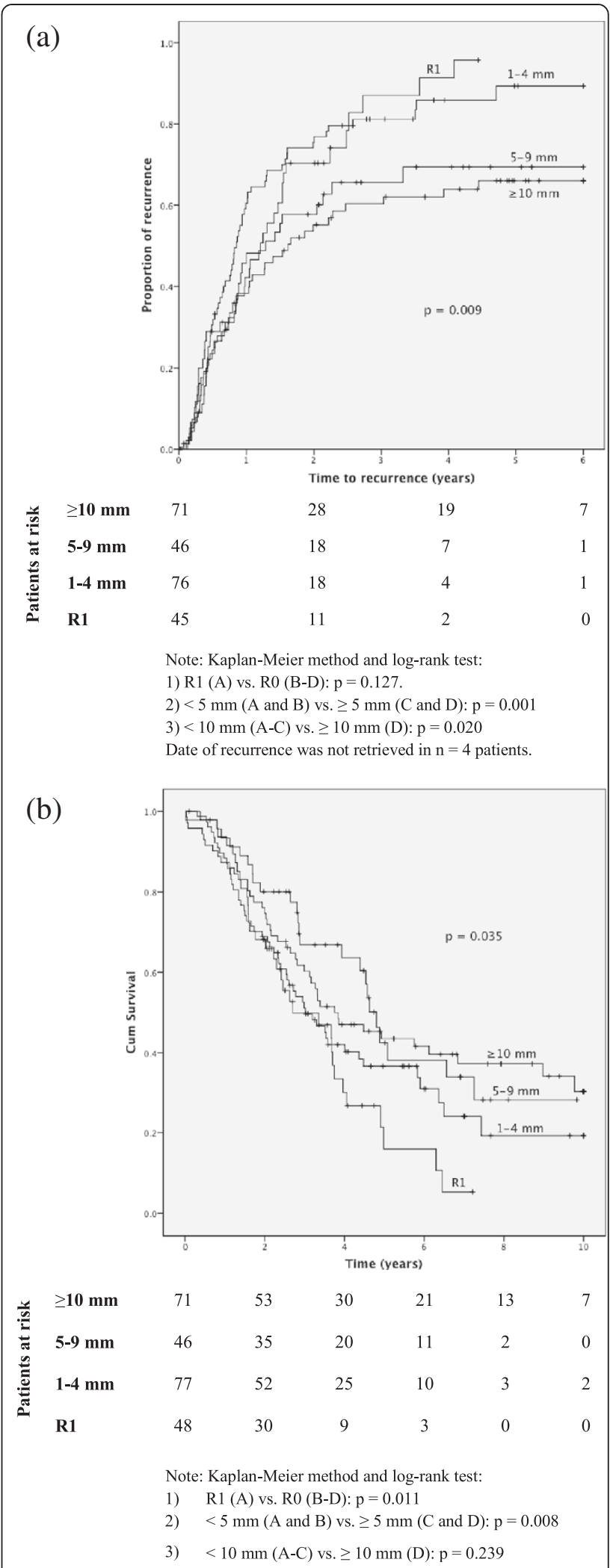

Figure 1 Time to recurrence (a) and overall survival (b) according to resection margins in $n=242$ patients with primary resection for colorectal liver metastases. 
model $(P=0.067)$, along with age, ASA score, number of metastases, size of the metastases and repeated resections (Table 4). When using the RM sub-groups (A to D) in the Cox model $(P=0.111)$ and the RMs as a continuous variable $(P=0.099)$, significance was not reached. We neither found any substantial differences in OS with a cut-off margin of $5 \mathrm{~mm}(P=0.194)$. We also applied multiple fractional polynomials in the Cox regression model without identifying any non-linear relationships between RMs and OS. When adjusting for patients offered preoperative chemotherapy, multivariate analyses revealed RMs still to be a borderline significant factor predicting adverse OS $(P=0.081)$. However, in contrast to the rest, there was an adverse effect on OS of R1 vs. R0 in the downstaging group (test of interaction $P=0.020$ ), adjusting for the same variables as listed in Table 4 . No such effect was evident in the perioperative group.

Finally, we conducted survival calculations according to the site of recurrence and the involvement of LR independently of RMs. We could not reveal any difference in five-year OS between LR (total), hepatic-only and extrahepatic recurrence $(P=0.947)$. Patients with LR only proved a better five-year OS compared to patients with recurrence at other sites $(35.9 \%$ vs. $25.4 \%, P=0.048)$.
Within the latter group we neither found any substantial differences in OS $(P=0.130)$.

\section{Discussion}

The main finding in this study was that positive RMs influenced overall survival after resection for CLM. LR occurred more frequently and TTR was shorter in RMs $<5 \mathrm{~mm}$. Following preoperative chemotherapy, negative margins were still a prerequisite for achieving an improved survival.

Our study demonstrated that positive margins were related to a more dismal prognosis. This is consistent with the majority of other comparable reports [1,9,24-26]. Even with a consensus on obtaining free margins after liver resections there are still conflicting results about the sufficient magnitude of the RMs and its impact on recurrence and survival. Several studies have shown that local recurrence and survival were independent of the extent of the free margins $[8,9,11,27]$. In addition to the benefit of R0, we found an increasing OS and TTR in patients with RMs $>5 \mathrm{~mm}$ (Figures $1 \mathrm{a}$ and $\mathrm{b}$ ). No additional advantage was found for free RMs beyond this limit. In the report from Nuzzo et al. a RM $\leq 5 \mathrm{~mm}$ was associated with a greater risk of LR, as well as reduced disease-free survival

Table 4 Results from Cox regression analysis of resection margins and other factors affecting overall survival in 253 patients after primary resection for colorectal liver metastases

\begin{tabular}{|c|c|c|c|c|c|c|c|c|}
\hline & & \multirow[b]{3}{*}{$\mathrm{n}$} & \multicolumn{6}{|c|}{ Overall survival } \\
\hline & & & & Univariate & & & Multivariate & \\
\hline \multicolumn{2}{|l|}{ Variable } & & $\mathrm{HR}$ & $95 \% \mathrm{Cl}$ & $P$ & $\mathrm{HR}$ & $95 \% \mathrm{Cl}$ & $P$ \\
\hline \multicolumn{2}{|l|}{ Age/10 y } & 253 & 1.32 & $(1.12,1.54)$ & $<0.001$ & 1.29 & $(1.08,1.54)$ & 0.005 \\
\hline \multicolumn{2}{|c|}{ DFI, months } & 253 & 0.91 & $(0.80,1,03)$ & 0.122 & 0.91 & $(0.79,1.05)$ & 0.187 \\
\hline \multicolumn{2}{|c|}{ Number of metastases } & 253 & 1.19 & $(1.10,1.28)$ & $<0.001$ & 1.31 & $(1.17,1.45)$ & $<0.001$ \\
\hline \multicolumn{2}{|c|}{ Metastasis diam, cm } & 242 & 1.11 & $(1.03,1.19)$ & 0.006 & 1.09 & $(1.02,1.18)$ & 0.023 \\
\hline \multirow[t]{2}{*}{ RM status } & RO & 205 & 1.00 & Reference & & 1.00 & Reference & \\
\hline & $\mathrm{R} 1$ & 48 & 1.69 & $(1.14,2.51)$ & 0.014 & 1.53 & $(0.98,2.39)$ & 0.067 \\
\hline \multirow[t]{4}{*}{ T stage } & & & & & 0.931 & & & 0.897 \\
\hline & $\mathrm{T} 2$ & 25 & 1.00 & Reference & & 1.00 & Reference & \\
\hline & $\mathrm{T} 3$ & 180 & 1.10 & $(0.65,1.87)$ & & 0.99 & $(0.54,1.81)$ & \\
\hline & $\mathrm{T} 4$ & 34 & 1.11 & $(0.57,2.19)$ & & 0.88 & $(0.40,1.90)$ & \\
\hline \multirow[t]{4}{*}{ N stage } & & & & & 0.506 & & & 0.229 \\
\hline & NO & 91 & 1.00 & Reference & & 1.00 & Reference & \\
\hline & N1 & 103 & 1.19 & $(0.83,1.72)$ & & 1.32 & $(0.88,1.98)$ & \\
\hline & $\mathrm{N} 2$ & 51 & 1.27 & $(0.81,1.98)$ & & 1.49 & $(0.92,2.42)$ & \\
\hline \multicolumn{2}{|l|}{ ASA score } & 253 & 1.62 & $(1.20,2.19)$ & 0.002 & 1.61 & $(1.13,2.29)$ & 0.009 \\
\hline \multirow[t]{2}{*}{ Bilobar } & No & 159 & 1.00 & Reference & & 1.00 & Reference & \\
\hline & Yes & 94 & 1.38 & $(1.01,1.89)$ & 0.048 & 1.22 & $(0.80,1.86)$ & 0.353 \\
\hline \multicolumn{3}{|c|}{ Re-resections } & 0.78 & $(0.60,1.01)$ & 0.045 & 0.71 & $(0.52,0.97)$ & 0.016 \\
\hline
\end{tabular}

$\mathrm{HR}$, hazard ratio; $\mathrm{Cl}$, confidence interval; DFl, disease-free interval (time between resection of the primary tumor in the colon or rectum and the detection of hepatic metastases); RM, resection margin; T and N stage, analysis of primary tumor in colon or rectum; ASA, American Society of Anesthesiologists. Unknown T-stage $n=14$, unknown $N$-stage: $n=8$, unknown diameter of metastases: $n=11$. 
(DFS) and OS [13]. Likewise, Vandeweyer et al. demonstrated that a RM $>1 \mathrm{~mm}$ improved OS. However, a margin beyond $1 \mathrm{~mm}$ did not yield any detectable advantage in survival [28]. In a large series of 2,715 prospective collected patients Hamady et al. stated that $1 \mathrm{~mm}$ free margin was sufficient to obtain a five-year DFS of $33 \%$. An extra margin width did not provide DFS advantage in this study [29]. Konopke et al. showed that even though the size of the RMs did not affect overall survival, a resection margin below $3 \mathrm{~mm}$ increased hepatic and overall recurrence [30]. Wray et al. found that $\mathrm{RM}<1 \mathrm{~cm}$ was a powerful factor in increasing the risk for local and distant recurrence as well as DFS [31]. The result was, however, not confirmed in a multivariate setting when only R0 cases were included.

Several studies have through genetic techniques detected tumour DNA up to $4 \mathrm{~mm}$ from the tumour border, and thereby determining a rational basis for the extent of surgical excision [12,32-34]. We also demonstrated that RMs plays a key role in the development of LR independently of recurrence in other sites of the liver and/or extrahepatic (Tables 2 and 3) using multinomic logistic regression. Furthermore, no correlation was detected between RMs and intra- or extrahepatic relapse without LR involvement (Table 3). Surprisingly, we detected an increased risk for extrahepatic recurrence in patients with less than $5 \mathrm{~mm}$ free margins. We have no plausible explanation for this finding, and the results may suggest that RMs might be surrogates of the extent of the disease. This is also visualized through a fairly high level of recurrence $(89.4 \%)$ in the group B (1 to $4 \mathrm{~mm}$, Figure 1$)$, as $40.3 \%$ of these patients had extrahepatic recurrence (Table 2). We hypothesise that intra- or extrahepatic relapse (without LR involvement) is based on progression of preoperatively non-detectable micro-metastases and not the impact of RMs. Unlike our report, de Haas et al. found that R1 was associated with intrahepatic recurrence, whereas no difference in surgical margin recurrence was seen between R0 and R1 [14]. Likewise, in the multiinstitutional study of 1,669 patients by de Jong et al., R1 resection was associated with intrahepatic recurrence, whereas extrahepatic disease developed independently of margin status [3].

In the study by Are et al. the RMs were analysed as a continuous variable [35]. They found no difference in survival between positive margins and sub-centimetre resections $(P=0.31)$ in the multivariate analysis, whereas patients with $R M>1 \mathrm{~cm}$ had a significantly improved outcome. Nevertheless, the authors observed a favourable survival in sub-centimetre R0 resections, and they concluded that these patients should not be denied hepatic resections.

In some published articles, with initially marginally or non-resectable CLM receiving preoperative chemotherapy, the important role of free margins were found to be less important [14-16]. In the current study, we found an improved OS for R0 vs. R1 in patients receiving preoperative chemotherapy. Our data indicates that R0 resections should be strived for in these patients. This finding also corresponds with recently published studies [36,37]. In patients with initially unresectable metastases successfully treated with chemotherapy, positive margins predicted in the univariate model an adverse outcome $(P=0.017)$, but this finding was not evident in resectable patients offered perioperative chemotherapy $(P=0.502)$. In the multivariate analysis this difference was confirmed. In the first group, postoperative chemotherapy was administered more rarely (17.5\%) compared with the latter group (69.8\%). In other settings like stage III colon cancer, adjuvant chemotherapy regimens have proved to expose and reduce the recurrence rates $[38,39]$. We hypothesise the same mechanism in R1 patients, where adjuvant chemotherapy may suppress any remaining metastatic disease, leading to an increase in TTR and OS. This resembles the trial by Tranchart et al. [37].

An exact measurement of RMs is impeded by the application of surgical devices such as the ultrasonic aspirator, harmonic scalpel, and Kelly clamp-crushing technique, which removes a small rim of liver tissue during the transection. An overestimation of R1 cases might be the consequence $[9,14]$. Likewise, the invasive irregular growth pattern in liver metastases, combined with a rough transection surface, makes the histological examination less reliable in narrow margins. The increasing use of chemotherapy may also complicate the measurement of RMs due to a more irregular surface, as reported by Ng et al. [34].

Several studies have demonstrated an effect of R1 resections on OS in univariate analyses, but have not confirmed this finding in a multivariate setting $[9,13,35]$. This result has led to a discussion whether $\mathrm{R}$ status is a surrogate of other biologic factors such as size, number, growth patterns and distribution of the metastases, rather than an independent predictor for adverse outcome. In the current trial R1 was of borderline significance in the multivariate analysis $(P=0.067)$. However, a more advanced disease in patients undergoing R1 vs. R0 resection is reflected by a higher incidence of bilobar distribution and number of metastases. This is consistent with other recognized reports $[9,14,35]$. The advancement of disease reflected in number and size of metastases appears to have greater impact on survival than RMs. Based on our findings we advocate that R0 should be performed despite no clear significance in the Cox model. We also assume with a larger number of patients in the cohort, the significance might be obtained.

We reported a rather high incidence of LR (total) and global recurrence of 40 (16.5\%), and 175 (72.3\%) patients, 
respectively, which is somewhat higher than other studies $[9,12,13]$. The RMs (groups A to D) did not influence the TTR when patients with LR (total) were excluded from the analysis $(P=0.097)$. A similar finding in TTR was evident between R1/R0 ( $P=0.403)$. However, we could neither detect any worse OS in patients with LR (total) compared with patients with recurrence at other sites. A fairly high proportion of patients with LR were offered repeated resections with curative intent. In patients with LR only, 78.6\% underwent a second resection, following better OS compared with recurrence in other sites. We could not obtain a different OS among patients with relapse in other localisations. Despite a high recurrence rate, we have obtained a five-year OS of nearly $40 \%$ and a median OS of 45 months. We assume an aggressive multimodal treatment and with repeated resections in patients with advanced disease and marginally resectable metastases may be justified despite the high number of relapse [14]. Based on this, patients with suspected narrow RMs should not be excluded from resection for colorectal liver metastases.

\section{Conclusions}

A positive resection margin predicted adverse OS after resection for colorectal liver metastases. Likewise, local recurrence and time to recurrence were influenced by positive margins. In addition, an increasing survival rate, a reduced recurrence (local and global) rate and a longer time to recurrence were seen in patients with $\mathrm{RM}>5 \mathrm{~mm}$, but could not be verified beyond this extent. In an era with expanding use of chemotherapy, our study supports that R0 resections are still important in order to obtain the best outcome in patients treated with resection for colorectal liver metastases.

\section{Abbreviations \\ CEA: carcinoembryonal antigen; CLM: colorectal liver metastases; $C T$ : computed tomography; DFS: disease-free survival; LR: local recurrence; OS: overall survival; RM: resection margin; TTR: time to recurrence.}

\section{Competing interests}

The authors declare that they have no competing interests. There was no grant support for this study.

\section{Authors' contributions \\ All the authors have fulfilled the ICMJE guidelines, according substantial contribution to this study. JHA has been in charge of the data collection. All the authors have participated in the design, acquisition, data analysis and interpretations. GEE is a medical statistician, and has been in charge of the statistical calculations and interpretations of the collected data. All the authors have contributed in the drafting and have revised the manuscript critically before submission. They have all given their final approval of this version to be published, and take full responsibility for all the aspects and results in this manuscript.}

\section{Acknowledgements}

1) Department of Pathology, Haukeland University Hospital for permitting publication of the results from the histological report.

2) Dr Inger Marie Løes, Department of Oncology, Haukeland University Hospital for data collection and calculation of the RECIST criteria.

\section{Author details}

'Department of Acute and Digestive Surgery, Haukeland University Hospital, N-5021 Bergen, Norway. ${ }^{2}$ Department of Clinical Medicine, University of Bergen, N-5020 Bergen, Norway. ${ }^{3}$ Department of Research and Development, Centre for Clinical Research, Haukeland University Hospital, N-5021 Bergen, Norway. ${ }^{4}$ Department of Global Public Health and Primary Care, University of Bergen, N-5020 Bergen, Norway.

Received: 30 November 2013 Accepted: 4 April 2014

Published: 27 April 2014

\section{References}

1. Fong Y, Fortner J, Sun RL, Brennan MF, Blumgart LH: Clinical score for predicting recurrence after hepatic resection for metastatic colorectal cancer - analysis of 1001 consecutive cases. Ann Surg 1999, 230:309-318.

2. Adam R, de Haas RJ, Wicherts DA, Vibert E, Salloum C, Azoulay D, Castaing D: Concomitant extrahepatic disease in patients with colorectal liver metastases when is there a place for surgery? Ann Surg 2011, 253:349-359.

3. de Jong MC, Pulitano C, Ribero D, Strub J, Mentha G, Schulick RD, Choti MA, Aldrighetti L, Capussotti L, Pawlik TM: Rates and patterns of recurrence following curative intent surgery for colorectal liver metastasis an international multi-institutional analysis of 1669 patients. Ann Surg 2009, 250:440-448.

4. Ekberg H, Tranberg KG, Andersson R, Lundstedt C, Hagerstrand I, Ranstam J, Bengmark S: Determinants of survivla in liver resection for colorectal secondaries. Br J Surg 1986, 73:727-731.

5. Cady B, Jenkins RL, Steele GD Jr, Lewis WD, Stone MD, McDermott WW, Jessup JM, Bothe A, Lalor P, Lovett EJ, Lavin P, Linehan DC: Surgical margin in hepatic resection for colorectal metastasis: a critical and improvable determinant of outcome. Ann Surg 1998, 227:566-571.

6. Elias D, Cavalcanti A, Sabourin JC, Lassau N, Pignon JP, Ducreux M, Coyle C, Lasser P: Resection of liver metastases from colorectal cancer: the real impact of the surgical margin. Eur J Surg Oncol 1998, 24:174-179.

7. Shirabe K, Takenaka K, Gion T, Fujiwara Y, Shimada M, Yanaga K, Maeda T, Kajiyama K, Sugimachi K: Analysis of prognostic risk factors in hepatic resection for metastatic colorectal carcinoma with special reference to the surgical margin. Br J Surg 1997, 84:1077-1080.

8. Muratore A, Ribero D, Zimmitti G, Mellano A, Langella S, Capussotti L: Resection margin and recurrence-free survival after liver resection of colorectal metastases. Ann Surg Oncol 2010, 17:1324-1329.

9. Pawlik TM, Scoggins CR, Zorzi D, Abdalla EK, Andres A, Eng C, Curley SA, Loyer EM, Muratore A, Mentha G, Capussotti L, Vauthey JN: Effect of surgical margin status on survival and site of recurrence after hepatic resection for colorectal metastases. Ann Surg 2005, 241:715-724.

10. Poultsides GA, Schulick RD, Pawlik TM: Hepatic resection for colorectal metastases: the impact of surgical margin status on outcome. HPB 2010, 12:43-49.

11. Hamady ZZR, Cameron IC, Wyatt J, Prasad RK, Toogood GJ, Lodge JPA: Resection margin in patients undergoing hepatectomy for colorectal liver metastasis: a critical appraisal of the $1 \mathrm{~cm}$ rule. Eur J Surg Oncol 2006, 32:557-563.

12. Kokudo N, Miki Y, Sugai S, Yanagisawa A, Kato Y, Sakamoto Y, Yamamoto J, Yamaguchi T, Muto T, Makuuchi M: Genetic and histological assessment of surgical margins in resected liver metastases from colorectal carcinoma - minimum surgical margins for successful resection. Arch Surg 2002, 137:833-840

13. Nuzzo G, Giuliante F, Ardito F, Vellone M, Giovannini I, Federico B, Vecchio FM: Influence of surgical margin on type of recurrence after liver resection for colorectal metastases: a single-center experience. Surgery 2008, 143:384-393.

14. de Haas RJ, Wicherts DA, Flores E, Azoulay D, Castaing D, Adam R: R1 resection by necessity for colorectal liver metastases is it still a contraindication to surgery? Ann Surg 2008, 248:626-636.

15. Tanaka K, Nojiri K, Kumamoto T, Takeda K, Endo I: R1 resection for aggressive or advanced colorectal liver metastases is justified in combination with effective prehepatectomy chemotherapy. Eur I Surg Oncol 2011, 37:336-343.

16. Ayez N, Lalmahomed ZS, Eggermont AMM, ljzermans JNM, de Jonge J, van Montfort K, Verhoef C: Outcome of microscopic incomplete resection 
(R1) of colorectal liver metastases in the Era of neoadjuvant chemotherapy. Ann Surg Oncol 2012, 19:1618-1627.

17. Eisenhauer EA, Therasse P, Bogaerts J, Schwartz LH, Sargent D, Ford R, Dancey J, Arbuck S, Gwyther S, Mooney M, Rubinstein L, Shankar L, Dodd L, Kaplan R, Lacombe D, Verweij J: New response evaluation criteria in solid tumours: revised RECIST guideline (version 1.1). Eur J Cancer 2009, 45:228-247.

18. Nordlinger B, Sorbye H, Glimelius B, Poston GJ, Schlag PM, Rougier P, Bechstein WO, Primrose JN, Euan TW, Finch-Jones M, Jaeck D, Mirza D, Parks RW, Collette L, Praet M, Bethe U, Van Cutsem E, Scheithauer W, Gruenberger T: Perioperative chemotherapy with FOLFOX4 and surgery versus surgery alone for resectable liver metastases from colorectal cancer (EORTC Intergroup trial 40983): a randomised controlled trial. Lancet 2008, 371:1007-1016.

19. Punt CJA, Buyse M, Kohne C-H, Hohenberger P, Labianca R, Schmoll HJ, Pahlman L, Sobrero A, Douillard JY: Endpoints in adjuvant treatment trials: a systematic review of the literature in colon cancer and proposed definitions for future trials. J Natl Cancer Inst 2007, 99:998-1003.

20. Kaplan EL, Meier P: Nonparametric-estimation from incomplete observations. J Am Stat Assoc 1958, 53:457-481.

21. Mantel N: Evaluation of survival data and two new rank order statistics arising in its consideration. Cancer Chemother Rep 1966, 50:163-170.

22. Cox DR: Regression models and life-tables. J Royal Stat Soc B Stat Methodol 1972, 34:187-220

23. Royston P, Sauerbrei W: A new approach to modelling interactions between treatment and continuous covariates in clinical trials by using fractional polynomials. Stat Med 2004, 23:2509-2525.

24. Altendorf-Hofmann ASJ: A critical review of the major indicators of prognosis after resection of hepatic metastases from colorectal carcinoma. Surg Oncol Clin N Am 2003, 12:165-192.

25. Choti MA, Sitzmann JV, Tiburi MF, Sumetchotimetha W, Rangsin R, Schulick $\mathrm{RD}$, Lillemoe KD, Yeo CJ, Cameron JL: Trends in long-term survival following liver resection for hepatic colorectal metastases. Ann Surg 2002, 235:759-765.

26. Tsim N, Healey AJ, Frampton AE, Habib NA, Bansi DS, Wasan $\mathrm{H}$, Cleator SJ, Stebbing J, Lowdell CP, Jackson JE, Tait P, Jiao LR: Two-stage resection for bilobar colorectal liver metastases: R0 resection is the key. Ann Surg Oncol 2011, 18:1939-1946.

27. Figueras J, Burdio F, Ramos E, Torras J, Llado L, Lopez-Ben S, Codina-Barreras $A$, Mojal S: Effect of subcentimeter nonpositive resection margin on hepatic recurrence in patients undergoing hepatectomy for colorectal liver metastases. Evidences from 663 liver resections. Ann Oncol 2007, 18:1190-1195

28. Vandeweyer D, Neo EL, Chen JWC, Maddern GJ, Wilson TG, Padbury RTA: Influence of resection margin on survival in hepatic resections for colorectal liver metastases. HPB 2009, 11:499-504.

29. Hamady ZZ, Lodge JP, Welsh FK, Toogood GJ, White A, John T, Rees M: One-millimeter cancer-free margin is curative for colorectal liver metastases: a propensity score case-match approach. Ann Surg 2014, 259:543-548.

30. Konopke R, Kersting S, Makowiec F, Gassmann P, Kuhlisch E, Senninger N, Hopt U, Saeger HD: Resection of colorectal liver metastases: is a resection margin of 3 mm enough? World J Surg 2008, 32:2047-2056.

31. Wray CJ, Lowy AM, Mathews JB, Park S, Choe KA, Hanto DW, James LE, Soldano DA, Ahmad SA: The significance and clinical factors associated with a subcentimeter resection of colorectal liver metastases. Ann Surg Oncol 2005, 12:374-380

32. Hayashi $\mathrm{H}$, Nabeshima $\mathrm{K}$, Hamasaki M, Yamashita $Y$, Shirakusa T, Iwasaki $\mathrm{H}$ : Presence of microsatellite lesions with colorectal liver metastases correlate with intrahepatic recurrence after surgical resection. Oncol Rep 2009, 21:601-607.

33. Holdhoff M, Schmidt K, Diehl F, Aggrawal N, Angenendt P, Romans K, Edelstein DL, Torbenson M, Kinzler KW, Vogelstein B, Choti MA, Diaz LA Jr: Detection of tumor DNA at the margins of colorectal cancer liver metastasis. Clin Cancer Res 2011, 17:3551-3557.

34. Ng JKS, Urbanski SJ, Mangat N, McKay A, Sutherland FR, Dixon E, Dowden S, Ernst S, Bathe OF: Colorectal liver metastases contract centripetally with a response to chemotherapy - a histomorphologic study. Cancer 2008, 112:362-371.
35. Are C, Gonen M, Zazzali K, DeMatteo RP, Jarnagin WR, Fong Y, Blumgart LH, D'Angelica M: The impact of margins on outcome after hepatic resection for colorectal metastasis. Ann Surg 2007, 246:295-300.

36. Andreou A, Aloia TA, Brouquet A, Dickson PV, Zimmitti G, Maru DM, Kopetz S, Loyer EM, Curley SA, Abdalla EK, Vauthey JN: Margin status remains an important determinant of survival after surgical resection of colorectal liver metastases in the era of modern chemotherapy. Ann Surg 2013, 257:1079-1088.

37. Tranchart H, Chirica M, Faron M, Balladur P, Lefevre LB, Svrcek M, de Gramont A, Tiret E, Paye F: Prognostic impact of positive surgical margins after resection of colorectal cancer liver metastases: reappraisal in the era of modern chemotherapy. World J Surg 2013, 37:2647-2654.

38. Moertel CG, Fleming TR, Macdonald JS, Haller DG, Laurie JA, Goodman PJ, Ungerleider JS, Emerson WA, Tormey DC, Glick JH, Veeder MH, Mailliard JA: Levamisole and fluorouracil for adjuvant therapy of resected colon carcinoma. N Engl J Med 1990, 322:352-358.

39. Andre T, Boni C, Mounedji-Boudiaf L, Navarro M, Tabernero J, Hickish T, Topham C, Zaninelli M, Clingan P, Bridgewater J, Tabah-Fisch I, de Gramont A: Oxaliplatin, fluorouracil, and leucovorin as adjuvant treatment for colon cancer. N Eng/ J Med 2004, 350:2343-2351.

doi:10.1186/1477-7819-12-127

Cite this article as: Angelsen et al:: Surgery for colorectal liver metastases: the impact of resection margins on recurrence and overall survival. World Journal of Surgical Oncology 2014 12:127.

\section{Submit your next manuscript to BioMed Central and take full advantage of:}

- Convenient online submission

- Thorough peer review

- No space constraints or color figure charges

- Immediate publication on acceptance

- Inclusion in PubMed, CAS, Scopus and Google Scholar

- Research which is freely available for redistribution 